\title{
Developing a Model for Foot Anthropometric Descriptors for the Design of Prosthesis and Footwear in Nigeria
}

\author{
MONYE, IS; “ OMOTEHINSE, SA \\ Department of Production Engineering, University of Benin, Benin City, Nigeria \\ *Corresponding Author Email: drsamayodeji@gmail.com; Tel: +234-803-597-1630 \\ Other Author Email: chimdinma123@gmail.com
}

\begin{abstract}
Foot structure has been known to vary, consequently, there is need for anthropometric data update. The objective of this study is to develop a model of foot anthropometric descriptors for the design of prosthesis and footwear in Nigeria using craft questionnaires structured with Likert's 5-point attitudinal scale which was administered to 100 respondents and the corresponding data analyzed with Kendall's Coefficient of Concordance (KCC) and Principal Component Analysis (PCA). Thirteen judges ranked the 36 foot anthropometric descriptors in descending order of importance. The data revealed footwear safety $(0.811)$, technology enhancement $(0.811)$, footwear fitness $(0.810)$, Joint girth (0.794) and change in lifestyle (0.768) as dominant descriptors based on their factor loadings. This study showed that foot anthropometry is an important science for designing prosthetic and foot wears that can achieve the desired fit and comfort.
\end{abstract}

\section{DOI: https://dx.doi.org/10.4314/jasem.v23i12.13}

Copyright: Copyright (C) 2019 Monye and Omotehinse. This is an open access article distributed under the Creative Commons Attribution License (CCL), which permits unrestricted use, distribution, and reproduction in any medium, provided the original work is properly cited.

Dates: Received: 30 November 2019; Revised: 20 December 2019; Accepted: 23 December 2019

Keywords: Plantar pressure, Foot anthropometry, Prosthesis, Footwear, Descriptors

Data on modeling foot Anthropometric descriptors for the design of prosthesis and footwear in Nigeria are rare. This situation has therefore established a yawning crevasse for the development of foot Anthropometry that can serve as baseline for the design of prosthesis and footwear. Foot Anthropometry has shown that foot dimensions vary widely with individuals and the import is that the design of foot wears even prosthesis must consider those variations in order to achieve the desired fitness. Previous studies focused attention more on the estimation of stature (height), prediction of footwear fit as well as gender (sex) from foot dimensions/measurements. The selling point of this research lies in the fact that it will examine a gamut of factors that help to define foot anthropometry with a view to discerning similarities in dissimilarities. Research interest in foot Anthropometry dates back to the $19^{\text {th }}$ century. The works of McConaill (1945); Isman and Inman (1969) examined the mechanism of the human foot; the talocrural and talacalcareal joints to the foot in order to determine the axis of rotation. They are seminal. Feng-Tsung and Der-Naau (1999) also stated that the property of shoe last design significantly impacts the fitness of the shoes produced. An examination of the relationship between the foot dimensions and weight of Turkish university students was carried out by Amil et al., (1997). Furthermore, Baba (1975), also conducted a study on foot measurement for shoe construction with reference to the relationship between the foot dimensions. Other studies include quantitative comparison of foot Anthropometry and shape under different weight bearing conditions by Tsung (2003) and Oladipo et al., (2008) respectively. Sexual dimorphism in foot dimensions among adult Nigerians was carried out by Bob-Manuel and Didia (2008). Obikili and Didia (2006) also conducted a study on foot dimensions of a young adult Nigerian population. Ozden et al., (2005); Jitender (2010); Krishnan et al., (2011); Sonali (2012) carried out studies on the estimation of stature (height) from foot measurements. Similarly Ekezie (2013), established the foot Anthropometry of the Igbos in Nigeria, for height reconstruction, while sexual dimorphism and sex estimation from foot Anthropometry were conducted by Danboro and Elukpo (2008) and Reena et al., (2012). Furthermore, Nacher et al., (2005) described the development of a model for predicting footwear fit on the basis of user data. Ante et al., (2006) investigated the relationship between foot Anthropometrical and biomechanical descriptors for Croatian population. Tang and Hui (2011) proposed a fast approach to model foot deformation, while Albert and Ahmed (2012) presented a low cost effective lower limb prosthesis for use in baghdad, Iraq. Recent studies recorded by Hairunnisa et al., (2013), Neetu and Khatri (2015) and Tejas et al., (2015) were on the estimation of stature from Anthropometric measurements. Mustafa et al., (2013) reported a work on modeling and stress 
analysis of a normal foot-ankle and a prosthetic footankle complex. While Kandil et al., (2014) investigated the differences in plantar pressure distribution in normal subjects. In addition to the above, Choukou et al., (2014) proposed to reduce mechanical stresses resulting from inadequate safety shoe wearing. Samaila et al., (2015) measured the anthropometric parameters of foot of adult males and females Ga'anda people, Adamawa Nigeria. It is evident from the foregoing that there is a balance of literature especially in the area of assessment of foot Anthropometric descriptors for Nigerian adult population. Accordingly, the objective of this study is to develop a model of foot anthropometric descriptors for the design of prosthesis and footwear in Nigeria.

\section{MATERIALS AND METHODS}

Thirty six scale items were identified through an extensive survey of literature and were used to craft a set of questionnaires that were administered to respondents. Thirteen judges were selected who ranked the first set of questionnaires in descending order of importance and the respondents scores were collated into data matrix having a dimension of 13 by 36. Kendall's Coefficient of Concordance (KCC) denotes the index of consistency in ranking. In order to validate (assess) how consistent the judges were in ranking the scale items, Chi-square $\left(\chi^{2}\right)$ was used.

The $\chi^{2}$ - test guided the application of hypothesis. $H_{0}:$ Judges ranking are discordant

$H_{1}$ : Judges ranking are consistent

Decision Rule: (Test of Hypothesis): If $\chi_{\text {cal }}^{2}>\chi_{\text {tab }}^{2}$, we fail to accept the null hypothesis $\left(H_{0}\right)$

The $\mathrm{KCC}(\mathrm{W})$ is given by:

$$
\begin{aligned}
& W=\frac{S}{\frac{1}{12} K^{2}\left(N^{3}-N\right)} \\
& S=\sum\left(R_{j}-\frac{\sum R_{j}}{N}\right)^{2}
\end{aligned}
$$

Where, $N=$ Total number of variable $R_{j}=$ Column sum of ranks, $S=$ Variance

Kendall's coefficient of concordance (W), was computed using equation 1

Where, $\mathrm{S}=361861.8896, \mathrm{~K}=$ Number of judges $=13$, $\mathrm{N}=$ Number of factors being ranked $=36$

Substituting the above values into equation 1 :
$\mathrm{W}=\frac{361861.8896}{\frac{13^{2}}{12}\left(36^{3}-36\right)}=\frac{361861.8896}{656409.60}=0.55$

To test the significance of the KCC result, Chi-square $\left(\chi^{2}\right)$ was used and the equation is given as

$\chi_{\text {cal }}^{2}=\mathrm{K}(N-1) \mathrm{W}$

Where; $\mathrm{k}=13$ judges, $\mathrm{W}=0.57$ and $\mathrm{N}=36$

$\chi_{\text {Cal }}^{2}=13(36-1) 0.55=250.25$

\section{RESULT AND DISCUSSION}

Result of Kendall's Coefficient of Concordance $(K C C)$ : The result of Kendall's Coefficient of Concordance (W) was obtained as 0.55 which is at the threshold of middling. The Chi-square $\left(\chi^{2}\right)$ result was also obtained as 250.25 . Comparing the calculated chi-square value with that of the tabulated value which is 49.802 , the following conclusion was made: Since $\chi_{\text {cal }}^{2}=250.25>\chi_{\text {tab }}^{2}=49.802, \quad$ our experimental data do not furnish enough evidence for us to accept $\mathrm{H}_{0}$. We therefore conclude that the Judges ranking is consistent. Table 1 shows the foot anthropometric descriptors ranked in order of importance by the Judges.

Result of Principal Component Analysis (PCA): From the scree plot figure 1 , it can be clearly seen that at eigenvalue of 1 , and component number 3 , the curvity tends to flatten out, which shows factors reduction from 36 to mere 3 .

Factor Interpretation: The varimax rotation, after 21 iterations, extracted three factors $F_{1}, F_{2}$ and $F_{3}$ from 36 scale items of foot anthropometric variable. Evidently, from the tableau, $F_{1}, F_{2}$ and $F_{3}$ represents the principal factors that help to define foot anthropometry, and hence creatively labeled constitutional miscellanies, Darwinia fitness and ecotype respectively. We shall now interpret the three factors in the accompanying text.

$F_{1}$ : Constitutional miscellanies: This regime clustered twenty two variables dealing with leg dimension, racial composition and structural build. The variables all wield positive factor loadings suggesting that it is a stocky factor. In this relation, joint girth wields the most influential factor loading of 0.794. This is followed by another three namely:

i. $\quad$ Change in lifestyle (0.768)

ii. Ornament $(0.765)$ and

iii. Community lifestyle (0.757) 
Table 1: Merit order sequentiality of 36 variables for foot anthropometric descriptors

\begin{tabular}{|c|c|c|c|c|c|}
\hline $\mathbf{S} / \mathbf{N}$ & $\mathbf{R j}$ & Variables & $\mathbf{S} / \mathbf{N}$ & $\mathbf{R j}$ & Variables \\
\hline 1 & 38 & Footwear comfort & 19 & 263 & Body height \\
\hline 2 & 51 & Footwear safety & 20 & 266 & The human society \\
\hline 3 & 56 & Footwear Fitness & 21 & 266 & Stance and gait \\
\hline 4 & 84 & Footwear Functionality & 22 & 269 & Foot ankle circumference \\
\hline 5 & 90 & Footwear form & 23 & 270 & Geographical location \\
\hline 6 & 117 & Technology enhancement & 24 & 281 & Aesthetic limitation \\
\hline 7 & 123 & Satisfaction & 25 & 301 & Navicular bone \\
\hline 8 & 172 & Race & 26 & 311 & Foot Length \\
\hline 9 & 179 & Weight bearing condition & 27 & 319 & Nutrition \\
\hline 10 & 195 & Community Life style & 28 & 324 & Foot width \\
\hline 11 & 196 & Technical error & 29 & 329 & Change in lifestyle \\
\hline 12 & 199 & Flexibility & 30 & 332 & Heredity \\
\hline 13 & 205 & Footwear Price & 31 & 336 & Ethnic composition \\
\hline 14 & 209 & Foot height & 32 & 345 & Sexual differences \\
\hline 15 & 211 & Physical appearance & 33 & 371 & Joint girth \\
\hline 16 & 230 & Climatic factor & 34 & 372 & Stress and strain \\
\hline 17 & 233 & Individual Lifestyle & 35 & 379 & Biomechanical factors \\
\hline 18 & 259 & Ornaments & 36 & 397 & Muscle deformation \\
\hline
\end{tabular}

The result of the Varimax rotated factor matrix and the influential factor loadings are depicted in Table 2 .

Table 2: Result of Varimax Rotated Factor Matrix

\begin{tabular}{|c|c|c|c|c|}
\hline $\mathbf{S} / \mathbf{N}$ & Scale item (Variable) Description & $F_{1}$ & $\mathbf{F}_{2}$ & $\mathbf{F}_{3}$ \\
\hline 1 & Footwear functionality & & 0.759 & \\
\hline 2 & Footwear form & & 0.711 & \\
\hline 3 & Footwear Fitness & & 0.810 & \\
\hline 4 & Footwear Comfort & & 0.653 & \\
\hline 5 & Footwear Safety & & 0.811 & \\
\hline 6 & Satisfaction & & 0.657 & \\
\hline 7 & Individual lifestyle & 0.649 & & \\
\hline 8 & Ornaments & 0.765 & & \\
\hline 9 & Flexibility & & 0.684 & \\
\hline 10 & Technology Enhancement & & 0.811 & \\
\hline 11 & Physical Appearance & & & 0.606 \\
\hline 12 & Footwear Price & 0.674 & & \\
\hline 13 & Aesthetic limitation & 0.692 & & \\
\hline 14 & Geographical location & 0.694 & & \\
\hline 15 & Sexual differences & 0.737 & & \\
\hline 16 & Body height & 0.750 & & \\
\hline 17 & Change in lifestyle & 0.768 & & \\
\hline 18 & Nutrition & 0.711 & & \\
\hline 19 & Ethnic composition & 0.693 & & \\
\hline 20 & Foot length & 0.573 & & \\
\hline 21 & Foot width & 0.623 & & \\
\hline 22 & Foot height & 0.651 & & \\
\hline 23 & Foot ankle circumference & 0.704 & & \\
\hline 24 & Joint girth & 0.794 & & \\
\hline 25 & Community life style & 0.757 & & \\
\hline 26 & Race & 0.725 & & \\
\hline 27 & Climatic factor & & & 0.642 \\
\hline 28 & The human factor & 0.694 & & \\
\hline 29 & Muscle deformation & & 0.614 & \\
\hline 30 & Stress and strain & & 0.560 & \\
\hline 31 & Heredity & 0.757 & & \\
\hline 32 & Stance and gait & 0.735 & & \\
\hline 33 & Technical error & 0.562 & & \\
\hline 34 & Navicular bone & 0.725 & & \\
\hline 35 & Biomechanical factors & & & 0.648 \\
\hline 36 & Weight bearing condition & & 0.778 & \\
\hline
\end{tabular}




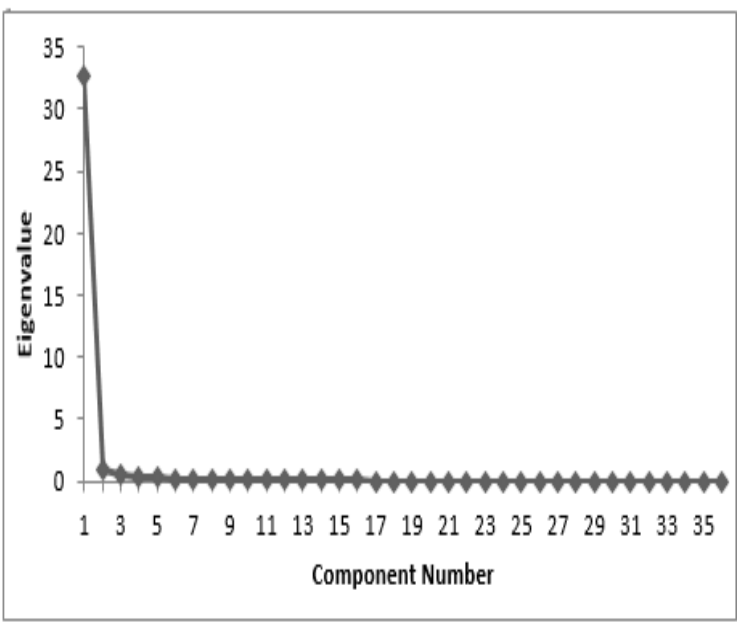

Fig. 1: Scree Plot

Table 3: Factor $1\left(\mathrm{~F}_{1}\right)$ Constitutional Miscellanies.

\begin{tabular}{llc}
\hline S/N & Variable description & Factor loading \\
\hline 7 & Individual lifestyle & 0.649 \\
8 & Ornaments & 0.765 \\
12 & Footwear price & 0.674 \\
13 & Aesthetic limitation & 0.692 \\
14 & Geographical location & 0.694 \\
15 & Sexual differences & 0.737 \\
16 & Body height & 0.750 \\
17 & Change in lifestyle & 0.768 \\
18 & Nutrition & 0.711 \\
19 & Ethnic composition & 0.693 \\
20 & Foot length & 0.573 \\
21 & Foot width & 0.623 \\
22 & Foot height & 0.704 \\
23 & Foot ankle circumference & 0.704 \\
24 & Joint girth & 0.794 \\
25 & Community life style & 0.757 \\
26 & Race & 0.725 \\
28 & The human society & 0.694 \\
31 & Heredity & 0.757 \\
32 & Stance and gait & 0.735 \\
33 & Technical error & 0.562 \\
34 & Navicular bone & 0.725 \\
\hline
\end{tabular}

These factor loadings are substantial suggesting that they bear meaningful, material and significant influence on footwear design and functionality. Clearly, change in lifestyle, be it community or individual, overtime, affect the quality of life of people. Good quality of life improves body stature generally. Sometimes it could lead to increase in body weight and we know that the entire weight of the body is supported on the feet of the individual. In the side of the ornament, though it does not per se affect the foot wear dimensions, it affects actually the aesthetics in terms of colour, fancy, attractiveness and appeal. The remaining variables which include genetic composition, ethnic diversity, and geographical location, all contribute immensely to footwear and prosthetic design. The next cluster, strange things, and creatively labeled Darwinian fitness, is also a sturdy factor.
Table 4: Factor $2\left(\mathrm{~F}_{2}\right)$ - Darwinian fitness

\begin{tabular}{llc}
\hline S/N & Variable Description & Factor loading \\
\hline 1 & Footwear functionality & 0.759 \\
2 & Footwear form & 0.711 \\
3 & Footwear fitness & 0.810 \\
4 & Footwear comfort & 0.653 \\
5 & Footwear safety & 0.811 \\
6 & Satisfaction & 0.657 \\
9 & Flexibility & 0.684 \\
10 & Technology enhancement & 0.811 \\
29 & Muscle deformation & 0.614 \\
30 & Stress and strain & 0.560 \\
36 & Weight bearing condition & 0.778 \\
\hline
\end{tabular}

Here eleven (11) variables are clustered with two variables footwear safety and technology enhancement wielding the most influential factor loading of $(0.811)$. This is evident from the fact that the safety of footwear is paramount to every user to prevent harm or injury to the foot. Technology enhancement has made possible the manufacture of sustainable and better foot wears, some of which have embedded sensors that can track distance travelled, calories burned and other biometric data. Proper fit comprises: foot Wear fitness (0.810), footwear functionality (0.759), footwear comfort (0.653), satisfaction (0.657), and muscle deformation (0.614). If adequately designed gives footwear Maximum comfort, stability and satisfaction to the user. On the other hand footwear designed inadequately is a misfit; it degrades functionality and results in muscle deformation, thereby affecting the foot dimensions. When the foot is persistently underweight, bearing conditions, the heaviness of the object results in strain and stress on the foot. Finally, flexibility and form of footwear allow the foot to move as naturally as possible. Lack of flexibility (high rigidity) results in high resistance force during gait, thereby putting enormous strain on the ball muscles, causing pain and inflammation which affect the foot structure.

The next factor, a trio, is creatively labeled Ecotype

\begin{tabular}{llc} 
& \multicolumn{2}{c}{ Table 5: Factor 3 $\left(\mathrm{F}_{3}\right)-$ Ecotype } \\
\hline S/N & Variable description & Factor loading \\
\hline 11 & Physical appearance & 0.606 \\
27 & Climatic factor & 0.642 \\
35 & Biomechanical factors & 0.648 \\
\hline
\end{tabular}

In this compilation, three (3) variables are clustered with biomechanical factors, wielding the most influential factor loading of 0.648 . This variable which involves muscular activities results in mechanical stresses which alter the physiology of the foot. This is followed by another two variables, namely: (i) Climatic Factor (0.642) and (ii) Physical appearance (0.606)

In the side of climatic factor, footwear designs vary climatically as a result of weather changes, topography 
and soil and these influence body growth and development with subsequent influence on footwear design and functionality. Furthermore, physical appearance portrays the outward features in terms of the size and shape of the body which have corresponding impact on the design of foot wears. It is evident from this study that so many descriptors tend to influence or should be taken into consideration while designing footwear and prosthesis. On all counts, foot anthropometry is an important science for designing prosthetic and foot wears that can achieve the desired fit and hence comfort. The study therefore has provided a veritable basis for designing foot aids that can engender comfort in walking.

Conclusion: This study has revealed that the Kendall's Coefficient of Concordance and Principal Component Analysis model adopted was successful in ranking the variables and achieving parsimony in factor reduction from thirty-six variables to mere three principal factors creatively labeled constitutional miscellanies, Darwinia fitness and ecotype that influence the design of prosthesis and footwear. In addition, the model provided insight into the merit order sequentiality and the way the variables interplay.

\section{REFERENCES}

Albert, EY; Ahmed, AS (2012). The design, development and construction of an adjustable lower extremity. IOSR J. of Eng. (IOSRJEN). 2(10): $30-42$.

Anil, A; Peker, T; Turgut, HB; Ulukent, SC (1997). An examination of the relationship between foot length, foot breadth; ball girth, height and weight of Turkish university students aged between 17 and 25. Anthropol ANZ SS(1): $79-$ 87.

Ante, A; Vasilije, N; Budimir, M (2006). Foot anthropometry and morphology phenomena. Coll. Anthropol 30 (4): 815 - 821.

Baba, K. (1974). Foot measurement for shoes construction with reference to the relationship between foot length, foot breadth, and ball girth. J. human ergol. 3(2): 149 - 156.

Bob-Manuel, I; Didia, B. (2008). Sexual dimorphism in foot Dimensions Among Adult Nigerians. The internet J. of Biological Anthrop. 3(1): 1-6.

Cheng, FT; Perng, DB (1999). A systematic approach for developing a foot size information system for shoe last design. Int. J. of ind. Erg. 25: 171 -185 .
Chiroma, SM; Philip, J; Attah, OO; Dibal, NI (2015). Comparison of the foot height, length, breadth and foot types between males and females Ga'anda people, Adamawa, Nigeria IOSR J. of dental and medical sci. (IOSR-JDMS), Vol. 14, issue 8, version 1, pp. 89-93.

Choukou, MA; Ghouli, S; Boyer, FC; TaiarChoukou, $\mathrm{R}$ (2014). Effects of unstable footwear on stance pattern. J. of Biosciences and medicines, 2. pp. $20-24$.

Danboro, B; Elukpo, A (2008). Sexual dimorphism in hand and foot length, indices, stature Ratio and relationship to height in Nigerians. The int. J. of forensic sci. 3(1): 1-5.

Ekezie, J (2013). Foot Anthropometry; A forensic and prosthetic application. Int. $j$. of sci. and research (IJSR), 4(6): $738-746$.

Hairunnisa, BMK; Moorthy. TN (2013). Stature estimate from the Anthropometric Measurements of foot outline in adult indigenous melanin Ethnics of east Malaysia by regression analysis. Sri Lanka $J$. of forensic medicine science and Law, 4(2): 27-35.

Isman, RE; Inman; VT (1969). Anthropometric studies of the human foot and ankle. Bulletin of prosthesis Research-spring, pp 97- 129.

Jitender, KJ (2010). Estimation of height from measurement of foot length in Haryana region. Journal of Indian Academy of forensic Medicine. 32 (3): 231 - 233.

Kandil, OD; Aboelazin, SN; Mabrouk, MS (2014). Foot Biometrics: Gender Differences in planter pressure Distribution in standing position. American Journal of Biomedical Engineers, 4 (1): 1-9.

Krishnan, K; Sharma, A (2007). Estimation of stature from dimension of hands and feet in a North Indian population. J. Forensic, Legal Med; 14; $327-332$.

MacConaill, MA (1944). The postural mechanism of the human foot. Royal Irish Academy. 50. 265278.

Mustapha, O; ONURS; Hassan, H (2013). Modelling and stress analysis of a normal foot- ankle and a prosthetic foot-ankle complex. Acta of Bioengineering and Biomechanics. 15 (3) 1927. 
Nacher, B; Alemany, S; Gonzalez, J.C; Alcantara, E; Garcia, J; Hernanadez, S; Heras, A. Juan (2006). A footwear fit classification model based on Anthropometric Data. DHM. 01 2356.

Neetu, P; Khatri, JK (2015). A predictive role of foot length in estimation of stature in western Rajasthan population scholars. J. of Applied Medical Sciences 3 (43): 1739 - 1740.

Obikili, EN; Didia, BC (2006). Foot dimensions of a young adult Nigerian population. Anatomical Society of Eastern Nigeria, 1. 22-24.

Oladipo, G; Bob-manuel, I; Ezenatein, G (2008). Quantitative Comparison of foot Anthropometry under different weight bearing conditions amongst Nigerians. The internet J. of Biol. Anthropol. 3(1): 1-11.

Ozden, H; Balci, Y; Demirüstü, C; Turgut, A; Ozden, EM (2005). Stature and sex estimate using foot and shoe dimensions. Forensic Sci. Int. 147(23): 181-184
Patel, TC; Parmar, AP; Bhagora, LR (2015). Productive role of foot Anthropometry for estimation of stature in females of Bhavnagar Gujarat. Int. J. Res Med, 4(4): 137-142.

Reena, S; Minu, B; Mrinal, B (2012). Sex estimation from foot anthropometry in Haryanvi jats and north Indian mixed population. J Punjab Acad Forensic Med Toxicol. 12 (1): 13-16.

Sonali, k; Ashish, R (2012). Estimation of stature from the measurement of foot length, hand length and head length in Maharashtra region. Indian J. Basic. Appl. Medic. Res. 2 (1). 77-85.

Tang, YM; Hui, KC (2011). Human Foot Modelling towards footwear design. CAD 43. 1841- 1848.

Tsung, BYS (2003). Quantitative comparison of planter foot shapes under different weightBearing conditions. J. Rehab. Res. Develop. 40(6): $517-526$. 